\title{
Remote learning among students with and without reading difficulties during the initial stages of the COVID-19 pandemic
}

\author{
Joanna Zawadka ${ }^{1}$ (D) Aneta Miękisz ${ }^{2}$ (D) - Iwona Nowakowska ${ }^{3}$ (D) \\ Joanna Plewko ${ }^{\text {(D) }} \cdot$ Magdalena Kochańska $^{5}$ (D) Ewa Haman²
}

Received: 30 January 2021 / Accepted: 19 April 2021 / Published online: 24 April 2021

(c) The Author(s) 2021

\begin{abstract}
This article presents the results of a survey on yet under-researched aspects of remote learning and learning difficulties in higher education during the initial stage (March - June 2020) of the COVID-19 pandemic. A total of 2182 students from University of Warsaw in Poland completed a two-part questionnaire regarding academic achievements in the academic year 2019/2020, living conditions and stress related to learning and pandemic, as well as basic demographic information, and Dyslexia Diagnosis Questionnaire (DDQ). The analyses were carried out in three sub-groups of students: who self-reported having a formal diagnosis of dyslexia (CDYS), self-reported reading difficulties, but had no formal diagnosis of dyslexia (SIDYS), and who reported no reading difficulties (CON). The results of the survey revealed that compared with the CON group, more students from CDYS and SIDYS groups did not pass at least one exam in the summer semester. CDYS and SIDYS groups experienced higher stress due to epidemiological restrictions, they had more difficulties than CON with the organisation of learning and obtaining credit during the COVID-19 pandemic. The results indicate a need for special consideration of additional support for students experiencing reading difficulties (whether or not they have a formal diagnosis).
\end{abstract}

Keywords COVID-19 $\cdot$ Dyslexia $\cdot$ Reading $\cdot$ Remote teaching $\cdot$ Remote learning . Higher education

Joanna Zawadka

joanna.zawadka@uw.edu.pl

Extended author information available on the last page of the article 


\section{Introduction}

The outbreak of the COVID-19 in March 2020 caused universities around the world to close the campuses and libraries, limit face-to-face contacts and switch to remote teaching in a very short time (Crawford et al., 2020; Zhao et al., 2020). Poland was no exception. This sudden need to rely only on web-based teaching can be looked at as an unexpected radical change in the way we approach learning and teaching. Although the new technologies allowing online learning already existed however, the majority of courses offered by universities were face-to-face courses and it was not that popular to incorporate new teaching/learning solutions offered by e-learning platforms (Zhao et al., 2020). Online learning evolved from distance learning (Moore et al., 2011) which was popularized in Europe by the Open University, established in the UK already in 1969 (Woodley, 1981; Zhao et al., 2020). There are an apparent diversity and lack of consensus on the terminology used to refer to learning over the internet. Distance learning, online learning, remote learning have been used interchangeably (see e.g. Chigeza \& Halbert, 2014; Ali, 2020; Carrillo \& Flores, 2020). We decided to use the term remote learning as opposed to the term online learning as there are opinions (e.g. Hodges et al., 2020 propose even a term "emergency remote teaching") that there is a need to distinguish between online teaching understood as planned in advance to remote teaching/learning which was implemented during the pandemic and was rather a spontaneous substitute of face to face approach.

Many educational institutions conducted online surveys to evaluate the level of satisfaction of remote learning, the effectiveness of remote teaching, and to learn how students were coping with stress related to the COVID-19 pandemic (Aristovnik et al., 2020; Demuyakor, 2020). The results generally indicate several factors playing an important role in efficient remote studying: availability of a good quality Internet infrastructure and digital equipment, teaching staff support, computer skills in using remote learning platforms and programs, living conditions, as well as motivation, self-discipline, and self-initiative (Aristovnik et al., 2020; Daniels et al., 2021; Zhu et al., 2020). The effectiveness and the ease of implementation of remote learning depended much on the prevalence of this form of learning before the COVID-19 pandemic (Aristovnik et al., 2020).

Although since the beginning of the COVID-19 pandemic, all students were undoubtedly affected by sudden and radical changes to all areas of their life, the group of students with developmental learning disabilities and other impairments deserves special consideration.

In their study, Forteza-Forteza et al. (2021) explored the learning processes of children/youth with dyslexia (aged 9-21, mostly from primary and secondary educational level) during the COVID-19 pandemic and the school lockdown. The authors argue that most pupils in their sample had access to technology, but only a small percentage had used applications that aided their reading, writing, and text comprehension. Despite the number of studies addressing the problems of students with reading difficulties (or more generally - students with learning disabilities) in the higher education context, only a small part of it refers to 
e-learning, distance learning, online learning etc. in students with dyslexia (Cataudella et al., 2021). To the best of our knowledge, to date no study has explored learning difficulties of any kind experienced by higher education students with dyslexia in remote learning during the COVID-19 pandemic. The aforementioned article of Forteza-Forteza et al. (2021) does not refer to individuals at the university level. And yet this group is potentially vulnerable to experience educational drawbacks due to the current situation. We aim to fill the research gap by looking at the situation of students with reading difficulties during the shift to remote learning due to the COVID-19 pandemic. There is a need to explore the situation of this group in order to prepare guidelines for developing university support and to implement changes in the educational process, if necessary.

\subsection{Literature review}

Dyslexia is a specific learning disability characterized by difficulties with accurate and fluent word recognition, poor decoding abilities, and/or poor spelling (WHO, 2015). In consequence, a person with dyslexia may have problems with reading comprehension, which in turn may lead to a reduced reading experience, limited growth of vocabulary and general knowledge (IDA, 2002). It has been documented that the gap in reading between typical readers and dyslexic readers persisted (despite an improvement) from early school years to adolescence (Ferrer et al., 2015; Shaywitz et al., 1999; Snowling et al., 2007) and adulthood (Reis et al., 2020; Snowling et al., 2020). Reis and colleagues (Reis et al., 2020) reviewed 178 studies of adults with dyslexia and concluded that compared to matched control groups the adults with dyslexia performed poorly on all of the writing and reading tasks except for reading comprehension. The authors point out the need for studies devoted to dyslexic adults as they experience life-long symptoms which are still far from being understood. Mortimore and Crozier (2006) have reported results of a survey administered among 136 students attending 17 higher UK education institutions. Notetaking, organisation of essays, and expressing ideas in writing were reported as academic skills that dyslexic students found difficult. It was also noted that although the difficulties had different patterns, they were experienced by those students also at earlier levels of education. Moreover, individuals with dyslexia may require more family support and professional help throughout their educational careers (Moojen et al., 2020) while facing not only difficulties in learning. Secondary symptoms such as high anxiety and low self-esteem are often present in children (Alexander-Passe, 2008) and maybe maintained in adults. Research results indicate a higher anxiety level in university students who were diagnosed with dyslexia compared to students without learning difficulties (Carroll \& Iles, 2006; Nelson et al., 2015; for contrary findings see: Lamm \& Epstein, 1992), lower self-esteem (Riddick et al., 1999). Moreover, dyslexia is often accompanied by other disorders. Rates of comorbidity between specific reading difficulties and other neurodevelopmental disorders varied in the range between 11 and 70\% (Moll et al., 2014, for an overview). Co-occurring disorders can modulate the severity of dyslexic difficulties over time and additionally modulate the symptoms of learning disabilities in the dyslexic population. 
Symptoms of dyslexia in adulthood may not be as severe as in childhood, but they still make an impact on a person's daily life and educational career achievements (Hellendoorn \& Ruijssenaars, 2000) that in turn is associated with worse perspectives of having stable, high skilled employment, and ultimate educational attainment (Maughan et al., 2020; Rutter \& Yule, 1975). Adults with dyslexia may present slower and more labour-intensive reading and writing (Beidas et al., 2013; Moojen et al., 2020; Suárez-Coalla \& Cuetos, 2015; Tops et al., 2013). Students with dyslexia may have difficulties in coordinating the sequence of actions when performing activities (Fawcett \& Nicolson, 2008; Stoodley \& Stein, 2013), difficulties in automating activities (Fawcett \& Nicolson, 1992), deficits in implicit learning (Menghini et al., 2006), difficulties with short term memory (Tamboer et al., 2017), and working memory (Jeffries \& Everatt, 2004). Due to the above-mentioned deficits, people with dyslexia may have problems with the organisation of their work and they need much more time to read and complete written tasks (Reid, 2016). For them, reading may not only be a tedious and tiring activity in itself, but they also may need to read the text many times to understand it (Reid, 2016). In their qualitative research Woodfine and colleagues (Woodfine et al., 2008) suggested that students with dyslexia experience a lack of confidence and encounter problems when engaged in textbased synchronous learning activities related to reading, spelling, sentence structure, transposition, memory, organisation, and time management. Taking this into account, one may expect that students with dyslexia will encounter greater difficulties than non-dyslexic students when learning online. Other research investigated the effects of different computer-based media in learning materials on the learning outcomes of individuals with and without dyslexia and pointed to possible advantages. The results of a study by Taylor et al. (2007) showed that animated learning materials have the potential to help students with and without dyslexia. According to the respondents, animated learning materials facilitate understanding concepts more than text or pictures. Beacham and Alty (2006) pointed out that different dyslexic students may benefit from using e-learning materials if the media used to present information corresponding to a particular preferred learning style. However, those benefits refer to particular materials and do not consider the complexity of the new approach to teaching and learning. It can be expected that even after the COVID-19 pandemic, hybrid/blended learning, which is a combination of online and classroom face-to-face instruction (Kaur, 2013; Chigeza \& Halbert, 2014) becomes a norm in the academic world. Therefore a holistic approach to its possible outcomes should be taken.

An unexpected implementation of remote teaching due to pandemic can be seen as a challenge and a chance to reveal which aspects of the new approach to teaching need to be further explored in order to assure equal learning opportunities for all the students.

Based on the literature related to the difficulties experienced by adults with dyslexia, and the exploratory nature of our study we propose the following hypotheses:

(H1) Dyslexic (CDYS) students struggle more than non-dyslexic students (CON, SIDYS) with effects of the pandemic (higher level of stress, lower academic achievement, more frequent reports of difficulties with remote learning). 
(H2) Group of students with self-diagnosed dyslexia (SIDYS) has more difficulties with remote learning than the control group $(\mathrm{CON})$, but less than the group with formal diagnosis (CDYS).

\subsection{The COVID-19 epidemic in Poland and its influence on higher education}

In Poland, the first confirmed case of COVID-19 was recorded on the 4th of March 2020 (Pinkas et al., 2020). As early as seven days later all Polish universities began suspending stationary classes and in the next few weeks they gradually transitioned to remote learning (Sidor \& Rzymski, 2020). On the 20th of March 2020 a state of epidemic emergency was declared (Pinkas et al., 2020). The strict restrictions of national quarantine lasted till the 20th of April 2020. In that time many lockdown-type control measures were introduced, among others: use of public spaces remained banned, citizens were encouraged to strict self-isolation and social distancing, social life and physical activities were reduced to the minimum, non-family gatherings were limited to two people, non-essential travel was forbidden, individuals were required to wear face coverings in public spaces and keep a social distance of minimum 1,5 m, minors were forbidden go outside unaccompanied. The state of epidemic emergency introduced in March-April 2020 influenced negatively the psychological well-being of Polish university students raising the level of depression, anxiety, and stress (Debowska et al., 2020; Rogowska et al., 2020; Szczepańska \& Pietrzyka, 2021; Talarowska et al., 2020; Wieczorek et al., 2021).

The functioning of higher education institutions was limited starting from the 12th of March until the 25th of March 2020. Since all universities were obliged to conduct solely remote learning, Rectors of many Polish universities issued the ordinance, which suspended the learning process until the 25th of March when the implementation of information and communication technologies (ICT) for the remote teaching process was to be accomplished. Although Moodle learning platforms had been used prior to the pandemic (Maleńczyk \& Gładysz, 2019; Półjanowicz et al., 2013; Rosak-Szyrocka \& Wojciechowski, 2015; Suchanska \& Keczkowska, 2007; Szadziewska \& Kujawski, 2017) not all academic teachers had experience in working with it neither with Google Suite for Education, Skype, Zoom nor with Microsoft Teams, etc. since the majority of curricula were realised in a stationary manner. Due to unexpected and rapid changes in the teaching and learning process many universities decided to conduct online surveys during the semester and after it, which were to investigate the perception of remote learning. The results showed that remote learning during the initial stage of the pandemic was considered less effective than face-to-face learning in terms of increasing skills and social competencies compared to traditional classes, students assessed their active participation during online classes to be lower (Bączek et al., 2021).

\subsection{Current study}

The general aim of our study was to explore the effects of the COVID-19 pandemic on the quality of learning, living conditions, academic performance, and stress levels of university students with special consideration of students with reading difficulties. 
In the current paper, we particularly analysed how students who experience reading difficulties cope with remote learning during the pandemic. We compared three groups of students: (1) students with a formal diagnosis of dyslexia (confirmed dyslexia, CDYS), (2) students who reported dyslexic difficulties but did not have an official diagnosis (self-diagnosed dyslexic symptoms, SIDYS), and (3) a group of students which did not report reading problems (control, $\mathrm{CON}$ ).

\section{Method}

\subsection{Participants and procedure}

The study was performed as a self-report anonymous survey conducted online between the 16th and 31st of July 2020 in one of the largest universities in Poland -University of Warsaw. The study was financed by an external grant, which aims at the improvement of existing and development of innovative solutions to increase the accessibility of education for students with disabilities. Thus, the study had the practical purpose of exploring the needs of a particular group of students. The strength of such an approach is that the policy of the university and ways of remote learning were the same for all of the participants. The conditions under which they learnt were thus similar, but at the same time, due to the variety of disciplines taught in this institution, the sample was diverse in terms of the fields of study such as science and humanities. The sampling was thus purposive (Teddlie \& Yu, 2007) and steps were taken to reach as large a number of students of the particular university as possible. Students were recruited through a central administration mailing list, encompassing all students of the university was used to disseminate the link, and social media (fan pages of faculties, student groups) as well as snowball approach. Social media were used as support in advertising the information about the survey. The study was prepared on Qualtrics XM. There was no time limit, it was possible to return to previous questions, as well as to save the answers and finish the survey later. The participants were not compensated for their participation. They were asked to generate an individual code that can be used to match participants' responses if they participate in scheduled follow-up studies.

All participants were of an average age of 22.55 years. Out of 3510 students who took part in the study, 2182 participants completed the whole set of questionnaires. Power analysis conducted in G*Power 3.1 (Faul et al., 2007, 2009) indicated that this sample size would allow for the detection of a large effect (0.4) in ANOVA analysis (alpha $=0.05$ ) with a power of 1.00 . Only 4 participants declared having a COVID-19 diagnosis but 465 (21\%) reported having self-diagnosed COVID-19 symptoms, 79 students were officially in quarantine. Majority of the participants $(1290,59 \%)$ were students of humanities, economics $(300,14 \%)$, formal sciences (232, 11\%), biology/medical $(67,3 \%)$ and $16 \%$ (293) were students from other, interdisciplinary fields. First-year students made up 38\% (823) of the whole group, second-year $-32 \%$ (676), third - 17\% (378), forth - 7\% (148) and fifth $-5 \%$ (113). Additionally, $26 \%$ of the respondents changed their place of living after the beginning of the COVID-19 pandemic. 
To identify students with possible reading problems, participants were asked whether they had dyslexia (formal diagnosis, self-diagnosis due to experienced reading difficulties, no diagnosis). 216 students declared having formal diagnosis (CDYS) and 201 reported reading difficulties but no formal diagnosis (SIDYS). A control group of students without reading difficulties (CON) was selected. To maximize the accuracy and power of the study, we matched participants belonging to the CON group to those belonging to the CDYS group by the use of the optimization algorithm (Kuhn, 1955) implemented via MATLAB (The Math-Works Inc. Natick, MA, USA). Table 1 presents general information describing the sample.

The participants were also asked whether they suffer from any neurodevelopmental disorder, behavioural disorder, or affective disorder. 60 participants $(27.8 \%)$ in the CDYS group, 47 students in the SIDYS group (23.4\%), and 11 participants $(5.1 \%)$ in the CON group declared having co-occurring disorders.

\subsection{Measures}

We used a two-part questionnaire. The first one aimed to collect basic demographic information, as well as information related to the issues concerning the sudden change from traditional to remote learning due to the COVID-19 pandemic such as increased stress due to the COVID-19 pandemic and due to remote learning, changes in work and living conditions, advantages and disadvantages of remote studying in the summer semester, and academic achievement (measured by success in passing the exams).

In the analysis presented below we mainly focus on students' answers to the following statements:

Dyslexia diagnosis. We asked students "Do you have a diagnosis of dyslexia?" and answers were: (1) Yes, (2) I do not have a formal diagnosis of dyslexia but I have such difficulties, (3) I do not have a formal diagnosis of dyslexia and I have no such difficulties.

Exam success. We asked students if they passed all the exams during the winter and summer semesters.

Table 1 General descriptive statistics of the sample

\begin{tabular}{lllll}
\hline General information & All & CON & CDYS & SIDYS \\
\hline Number of participants & 2182 & 216 & 201 & 216 \\
Mean age & 22.55 & 22.23 & 22.27 & 22.53 \\
Gender (female/male) & $1609 / 517$ & $133 / 72$ & $133 / 72$ & $138 / 53$ \\
COVID-19 positive (tested) & 4 & 0 & 0 & 1 \\
Job loss & 353 & 28 & 33 & 39 \\
COVID-19 symptoms in family members & 156 & 18 & 20 & 14 \\
Changed place of residence & 575 & 54 & 43 & 52 \\
Passed all exams in summer semester (PE) & 1555 & 41 & 71 & 68 \\
Did not pass all exams in summer semester (NPE) & 557 & 167 & 136 & 125 \\
\hline
\end{tabular}


Stress due to epidemiological restrictions. We asked students to score on a scale ranging from 1 to 100 , where 1 - nothing changed, 100 - a drastic increase, how much the epidemiological restrictions (implemented by the Polish government in March 2020) changed their level of general stress. A similar scale ranging from 1-100 was used by Zajenkowski and colleagues (Zajenkowski et al., 2020) to measure COVID-19-related phenomena.

Stress due to the forms of remote learning. We asked students to score the stress related to (1) different forms of passing subjects; (2) weekly homework; (3) the need to adapt to remote learning; from -2 (not stressful at all) to 2 (very stressful).

Amount of work needed to get credit. We asked students how much work they have to put into getting credit for the subjects in both semesters. They answered on a scale from 1 (very little) to 5 (a lot).

General difficulties due to remote learning. We asked students how they perceived difficulties related to (1) remote learning, such as adjusting the pace and time of work to their own needs; (2) contact with the lecturers; (3) general aspects of remote learning. They answered on a scale from 1 (I strongly disagree) to 5 (I fully agree with this statement) (the choice of items is supported by similar studies e.g. Abbasi et al., 2020; Adnan \& Anwar, 2020; Serhan, 2020).

For the full text of all the questions, see Table 2.

Additionally, in order to estimate the magnitude and presence of self-reported reading difficulties, Dyslexia Diagnosis Questionnaire (DDQ, original: Kwestionariusz Diagnozy Dysleksji, Bogdanowicz, 2012) was used. DDQ is a short, self-report questionnaire inspired by Adult Dyslexia Checklist (Smythe \& Everatt, 2001) and Vinegrad's Revised Adult Dyslexia Checklist (Vinegrad, 1994). Vinegrad's Revised Adult Dyslexia Checklist is a widely used, standardized questionnaire enabling to differentiate participants in terms of the intensity of reading difficulties (Snowling et al., 2012). The DDQ questionnaire consists of 30 items, e.g. Do you read slower than other people?; Do you have difficulties speaking, especially in stressful situations, for instance publicly?; Do you have difficulties in understanding the instructions that you read? The participants answer on a 4-point Likert scale ranging from 1 (definitely not) to 4 (definitely yes). In the current study, the alpha reliability for DDQ was Cronbach's alpha $=0.92$ (standardized $=0.92$ ).

\subsection{Statistical analysis}

All exploratory statistical analyses were conducted in SPSS 26.0 Statistics software for Macintosh. All the analyses were conducted on three groups based on dyslexia' diagnosis. The analysis of descriptive statistics was conducted to illustrate the demographic and other selected characteristics of the students responses.

For numeric variables, chi-square test was used and for continuous variables parametric tests for means (ANOVA with $\mathrm{S}-\mathrm{N}-\mathrm{K}$ post hoc comparison). The significance level was determined at $\mathrm{p}<0.05$. 


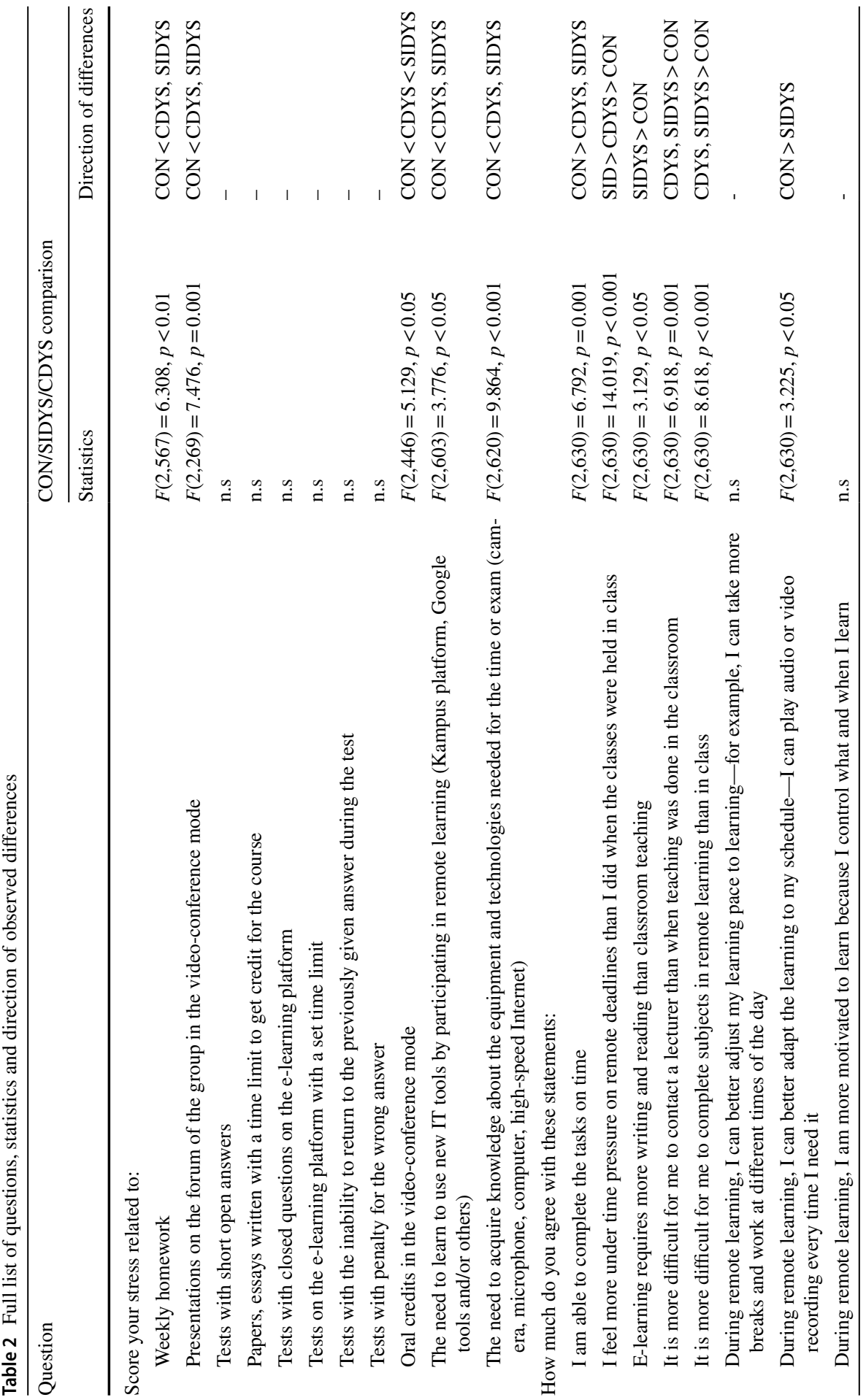




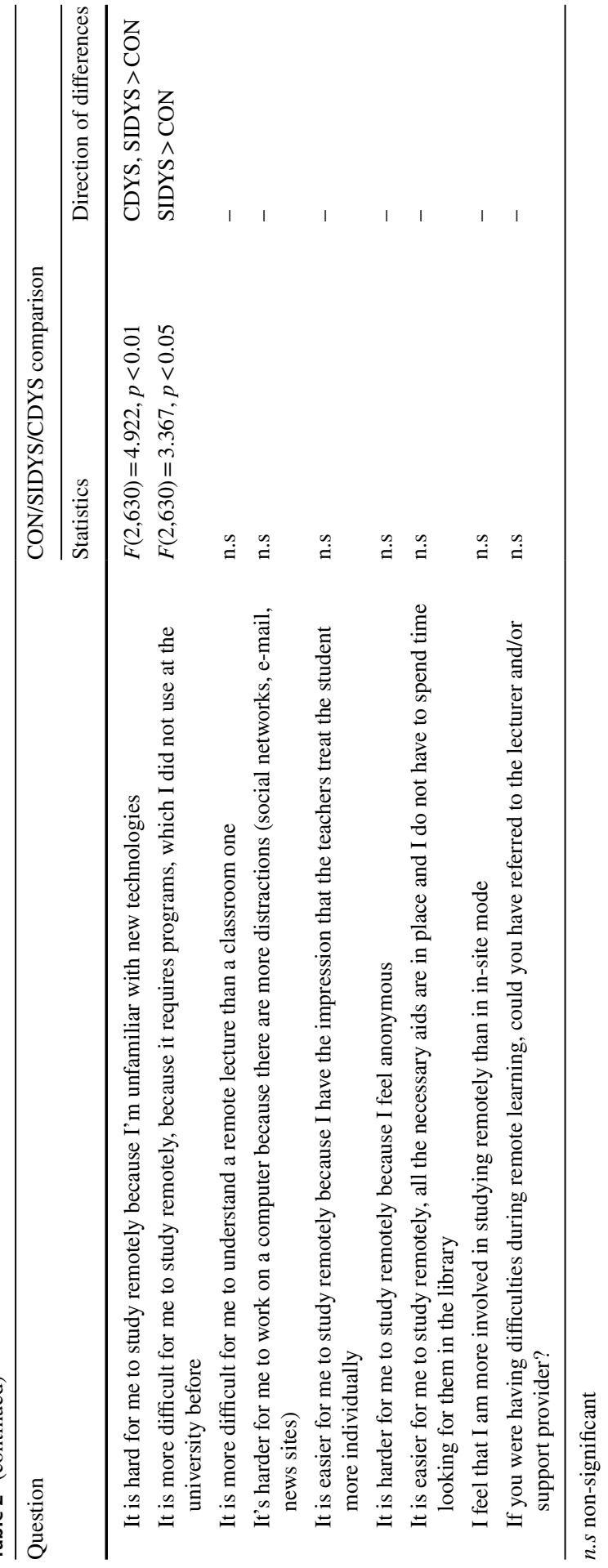




\subsection{Ethics}

The study materials and design have been approved by the University of Warsaw research ethics committee. The survey was conducted following the 1964 Declaration of Helsinki with later amendments. All participants provided informed consent and were informed about the possibility of quitting the survey anytime without consequences. The survey was distributed by the administrative staff of the University. The survey was not conditional on any type of student's evaluation connected to passing any classes and the format of the questionnaire did not allow to identify the student personal data nor learning outcomes.

\section{Results}

Analysis comparing the average score in symptoms of reading difficulties measured by DDQ (minimum $=30$, maximum $=120$ ) for three groups indicate that all the groups differ, $F(2,630)=123.98, p<0.001$, with $\mathrm{S}-\mathrm{N}-\mathrm{K}$ post-hoc comparison, alpha $=0.05$. CON having the lowest score and SIDYS the highest (Fig. 1).

Stress due to epidemiological restrictions CON students reported lower levels of stress-related to the epidemiological restrictions implemented by the government than CDYS and SIDYS groups $(F(2,610)=4.616, p=0.01$; post-hoc S-N-K alpha $=0.05$; see Fig. 2). The results support $\mathrm{H} 1$.

Stress due to the forms of remote learning Students' assessment of the level of stress related to different forms of getting course credit ranging from -2 (not stressful at all) to 2 (very stressful) differ for weekly homework $(F(2,567)=6.308$, $p<0.01$; post-hoc S-N-K, alpha $=0.05$; CDYS, SIDYS $>\mathrm{CON})$ as well as for the need to adapt to remote learning $(F(2,599)=7.915, p<0.001$; post-hoc S-N-K, alpha $=0.05$; CDYS, SIDYS $>$ CON). The results support $\mathrm{H} 1$.

See Table 2 for the full list of additional questions and statistics.

Exam success The comparison of the number of the students who did not pass all of the exams in the three groups (CDYS, SIDYS, CON) revealed that compared with the CON group more students from CDYS, $\chi^{2}=19.64, p<0.001$, and SIDYS, $\chi^{2}=21.96, p<0.001$, groups did not pass at least one exam in the remote, summer semester. The results support $\mathrm{H} 1$ and $\mathrm{H} 2$.

Perceived difference between winter and summer semester in the amount of work needed to get credit Paired $t$-test analysis confirmed that for all three groups, the summer semester (March - June 2020) required more work and commitment than the previous winter semester (September 2019 - January 2020), both for completing the classes, CDYS: $t(191)=2.070, p=0.04$; CON: $t(195)=4.154, p<0.001$; SIDYS: 
100

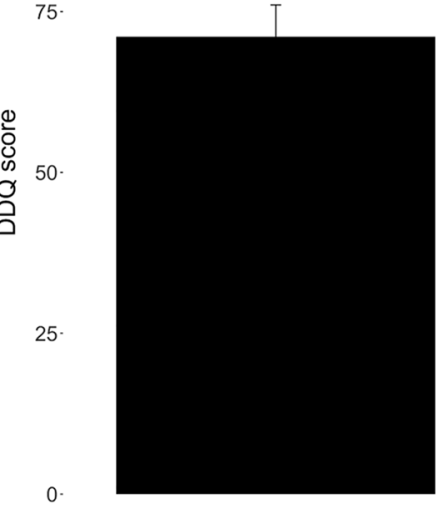

CDYS

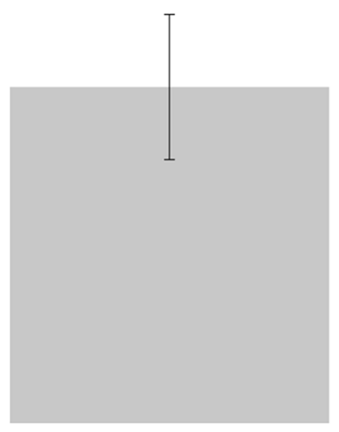

CON

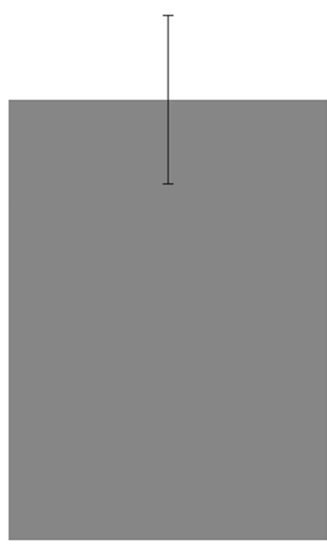

SIDYS

【CDYS CON $₫$ SIDYS

Fig. 1 The average DDQ score in groups of students who declared diagnosed dyslexia (CDYS), declared self-diagnosed dyslexia (SIDYS), and without dyslexia (CON)

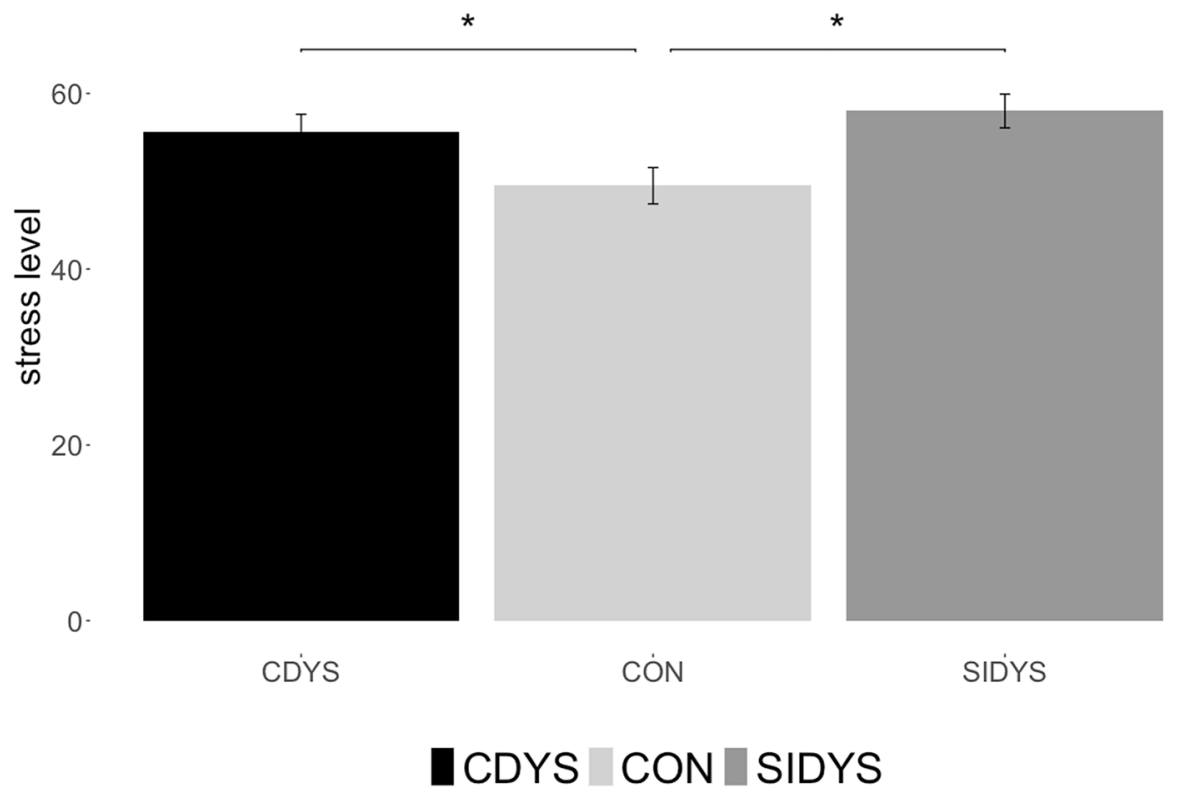

Fig. 2 Groups average stress levels related to the epidemiological restrictions due to the COVID-19 pandemic 
$t(186)=3.65, p<0.001$, and workshops, CDYS: $t(193)=2.111, p=0.036$; SIDYS: $t(185)=2.45, p=0.015$. The results support partially $\mathrm{H} 1$ and $\mathrm{H} 2$.

Difficulties in organisation of learning during the COVID-19 pandemic Students also differed in terms of perceived facilitations and limitations related to remote learning, such as adjusting the pace and time of work to their own needs, ease of contact with the lecturers, and other general aspects of remote learning. The main pattern of differences was that CDYS and SIDYS groups had more difficulties than CON. The results partially support $\mathrm{H} 1$ and $\mathrm{H} 2$. See Table 2 for the list of questions and detailed statistics.

\section{Discussion}

The COVID-19 pandemic has changed numerous areas of social life, including university education. Although studies on coping and the mental state of young adults during the pandemic in Poland are available (Debowska et al., 2020; Gambin et al., 2021; Nowakowska, 2020; Szczepańska \& Pietrzyka, 2021), our study was pioneering in terms of focus on students with reading difficulties, who might be differently affected by the pandemic and remote learning due to the character of their difficulties in reading and writing. The issue of computer-assisted learning and online learning in dyslexic students was elaborated previously but in different (nonpandemic) contexts (Pang \& Jen, 2018; Perelmutter et al., 2017; Woodfine et al., 2008). Students with dyslexia are present in a fair number at the university level and rising (López-Escribano et al., 2018; Mortimore \& Crozier, 2006; Pino \& Mortari, 2014) and thus understanding their situation during the remote learning period is worthwhile to support inclusion in university settings (for a review of the matter of inclusion of students with dyslexia in higher education see Pino \& Mortari, 2014). In the current study, we explored how they faced the new situation and what were their main challenges during the time of rapid change in the teaching and learning process due to the COVID-19 pandemic. The results of our study partially confirm the hypotheses that (H1) dyslexic students struggle more than non-dyslexic students with effects of the pandemic (higher level of stress, worse academic achievement, more frequent reports of difficulties with remote learning) and (H2) which stated that a group of students with self-diagnosed dyslexia (SIDYS) has more difficulties with remote learning than the control group (CON), but less than the group with formal diagnosis (CDYS). The current study has shown how students who self-reported having a formal diagnosis of dyslexia or reading difficulties without a formal diagnosis and controls, differed in terms of their perception of (1) level of stress (regarding epidemiological restrictions and regarding changes in the forms of learning), (2) the difference in the perceived amount of work needed to get credit, and (3) the general difficulties due to remote learning.

The comparisons of answers in three groups of students (CDYS, SIDYS and $\mathrm{CON}$ ), revealed significant differences. Our results indicate that there is indeed a need for looking into the issue of additional support for university students with reading difficulties due to changes in teaching introduced during the pandemic. Even 
before the pandemic period, it was indicated that such support is vital to enhance the functioning of dyslexic students at university (MacCullagh et al., 2017). During the pandemic, all students had to face new challenges, however the students from the control group (without reading problems) less often failed exams, had a lower level of perceived stress due to epidemiological restrictions and due to the forms of remote learning. The control group also reported fewer problems with remote learning. All groups (DYS, SIDYS, CON) claimed that the workload during the online semester was greater than during the in-site winter semester which can be due to the specificity of remote learning, lecturers' substantive and technical competencies related to the remote teaching as well as students' technical competencies. As a result of sudden changes in the first months of the COVID-19 pandemic, many academic lecturers in Poland could provide only (or mainly) asynchronous remote teaching in which students were given tasks for self-study based on written materials (Cicha et al., 2021). This form of teaching requires relatively more reading and writing, which may be one of the reasons underlying the intergroup differences observed. Also, later changes to more synchronous teaching (using videoconferencing) aimed at increasing students' active participation in remote learning by encouraging them to explore problems by themselves, collect needed information beforehand, and present the results of the research. At this point, the question arises whether the increased workload in participating and completing classes translates to higher effectiveness of learning and better learning outcomes? This however goes beyond the scope of the current analysis.

We would like to draw attention to the similarities of reported difficulties in groups with a formal diagnosis and those without, but reporting reading problems. In the case of some of the answers, the CDYS and SIDYS groups did not differ significantly, but they differed from the assessments presented by the CON group. In other cases, assessments of the respondents from SIDYS ranked even higher than CDYS. Both the discrepancy and equality of the assessments highlight the need for supporting students experiencing dyslexia-like difficulties who may have not received formal assistance and support due to the lack of documented history of learning difficulties. It further indicates that reading problems constitute a real issue that should be taken into account when we think about appropriate student services (Pirttimaa et al., 2015; Quick, 2013; Reis et al., 2020). Individuals without a formal diagnosis of dyslexia may have not obtained it at the elementary-school level because of a mild severity of their problems and the failure to meet all diagnostic criteria. The formal diagnosis of dyslexia may be a reason for seeking reading comprehension therapy, which may be beneficial to the compensating strategies for dyslexic problems (Cancer et al., 2020; Galuschka et al., 2014, 2020; Pape-Neumann et al., 2015). People who did not have a formal diagnosis but feel they experience difficulties might be therefore disadvantaged by the fact that they did not receive treatment in the past. Our findings advocate for inviting adult students without diagnoses, but reporting difficulties in learning to undergo an assessment of their strengths and weaknesses in academic functioning to receive appropriate support in the higher education context. We hope that our findings encourage exploration of possibilities for appropriate support for students with dyslexia as apparently students with reading difficulties also struggle more with learning during the pandemic. Further studies are needed 
in order to disentangle the effects of new approaches to teaching and those due to pandemic.

\subsection{Limitations}

Our work has several limitations that need to be taken into account when interpreting the results of the study. Firstly, the participants were students of one of the largest and most renowned universities in Poland therefore their reading skills might have been generally high. However, if we were able to obtain such differences in this population of highly functioning students, it only supports the need for further investigation of these issues in different educational settings. It should also be noted that the study was cross-sectional, making it impossible to form any causality statements and limiting the scope of understanding how people coped with learning before the COVID-19 pandemic. Moreover, the study based on self-report of reading problems, which might have made it difficult for some individuals to disclose the problems they encounter in real life, even though the study was anonymous and independent from academic assessment (there is a similar concern about their report of comorbid disorders). Stress-related variables were also measured with single items, which might have limited the scope of understanding the nuances of stress experienced by the students. In the interpretation of the results related to the problems with technical aspects of the remote learning, we did not control the level of technological skills prior to COVID-19 pandemic. We need to rely on knowledge that we have about the general situation in Poland and at the investigated university. Poland seems to be similar to other countries in terms of e.g. availability of resources to learn how to use digital devices and in some aspects (e.g. computer access) even exceeded averages across OECD countries (Organization for Economic Co-Operation and Development). As for the University of Warsaw since the establishment in 1999 of The Centre for Open and Multimedia Education (currently Digital Competence Center) new technologies are present and available to University of Warsawcommunity, including e-learning and online teaching. This unit provided very broad support and training long before the COVID-19 pandemic. However, the online courses were only supporting the on-site classes, whereas the pandemic moved all interactions and all courses to a remote mode.

\subsection{Future research directions}

We postulate to continue research on the impact of the COVID-19 pandemic on learning and teaching at the universities, by the use of standardized questionnaires, as well as surveys tailored to the circumstances in which the students function in a given higher education institution. The question is whether the disproportions in problems experienced by students with and without reading difficulties will be observable even after the COVID-19 pandemic, when the on-site classes will be returned (even to some extent) or when the COVID-19 threat will be lowered (e.g., after vaccinating the population of students). It is also interesting whether now disadvantaged groups like students with dyslexia (or more 
broadly saying-with specific learning difficulties) would be further disadvantaged due the remote learning as the pandemic continue or will they accumulate some experience in remote learning which may facilitate the learning process and increase learning outcome as suggested by Orlov and colleagues (Orlov et al., 2021). To find this out, in the future, it would be advisable to continue similar research, as well as include standardized measurements of distress related to the COVID-19 pandemic. Careful examination of pitfalls of rapid change in the ways of remote teaching and learning at the universities, especially concerning students with special needs (as students with dyslexia), may help in establishing new effective teaching methods (new e-learning approach) once the COVID-19 pandemic is over.

We can expect that after the COVID-19 pandemic, hybrid/blended learning becomes a norm in the academic world. This change from traditional teaching to a new e-learning approach (understood as much broader use of different technologies than offered by remote learning) raises challenges to lecturers and students due to its magnitude and time-frame of implementation (Almaiah et al., 2020; Pham \& Ho, 2020). Therefore, we should pinpoint possible advantages and disadvantages that might be faced by faculty and students, especially for those who are the most vulnerable, students with learning difficulties. We are convinced that future research needs to adopt a very broad approach and take advantage of new technologies which have been already demonstrated as useful for supporting students with learning difficulties (Pang \& Jen, 2018; Perelmutter et al., 2017; Taylor et al., 2007).

Authors' contributions Joanna Zawadka: Conceptualization, Methodology, Writing - original draft, Writing - review and editing, Supervision.

Aneta Miękisz: Conceptualization, Methodology, Writing - original draft, Writing - review and editing.

Iwona Nowakowska: Conceptualization, Investigation, Resources, Writing - original draft, Writing review and editing, Project administration.

Joanna Plewko: Conceptualization, Methodology, Formal analysis, Investigation, Data curation, Writing - original draft, Writing - review and editing.

Magdalena Kochańska: Conceptualization, Methodology, Writing - review and editing.

Ewa Haman: Conceptualization, Methodology, Writing - review and editing, Supervision.

Funding The work is based on material gathered for the purposes of applying novel instruments for the functional diagnosis of students with dyslexia at the University of Warsaw. The task of designing these instruments was co-financed by the European Union: European Social Fund with a grant no. POWR.03.05.00-00-A067/19-00 awarded to University of Warsaw Office for Persons with Disabilities. All co-authors were formally involved in this task.

Data availability Data and material are available on reasonable request.

Code availability Code is available on reasonable request.

\section{Declarations}

Ethics approval The study materials and design have been approved by the University of Warsaw research ethics committee. The survey was conducted following the 1964 Declaration of Helsinki with later amendments. All participants provided informed consent and were informed about the possibility of quitting the survey anytime without consequences. 
Consent to participate All participants provided informed consent prior to the study.

Consent for publication All participants were informed and consented prior to the study to the possibility of publication of the analysis of results. The submission complies to the regulations of publishing research at the places of affiliation of the authors and at the University of Warsaw.

Conflict of interest/Competing interests At the time of study conduction, JZ, AM, IN, JP, were the employees of the grant at the University of Warsaw mentioned in the Funding section at the time of study conduction and submission of this version of the manuscript. EH was an employee of this grant at the time of study conduction. MK was an employee of this grant at the time of submission of this version of the manuscript.

Open Access This article is licensed under a Creative Commons Attribution 4.0 International License, which permits use, sharing, adaptation, distribution and reproduction in any medium or format, as long as you give appropriate credit to the original author(s) and the source, provide a link to the Creative Commons licence, and indicate if changes were made. The images or other third party material in this article are included in the article's Creative Commons licence, unless indicated otherwise in a credit line to the material. If material is not included in the article's Creative Commons licence and your intended use is not permitted by statutory regulation or exceeds the permitted use, you will need to obtain permission directly from the copyright holder. To view a copy of this licence, visit http://creativecommons.org/licen ses/by/4.0/.

\section{References}

Abbasi, S., Ayoob, T., Malik, A., \& Memon, S. I. (2020). Perceptions of students regarding e-learning during Covid-19 at a private medical college. Pakistan Journal of Medical Sciences, 36(COVID19S4), S57. https://doi.org/10.12669/pjms.36.COVID19-S4.2766

Adnan, M., \& Anwar, K. (2020). Online learning amid the COVID-19 pandemic: Students' perspectives. Journal of Pedagogical Sociology and Psychology, 2(1), 45-51. https://doi.org/10.33902/JPSP. 2020261309

Alexander-Passe, N. (2008). The sources and manifestations of stress amongst school-aged dyslexics, compared with sibling controls. Dyslexia, 14(4), 291-313. https://doi.org/10.1002/dys.351

Ali, W. (2020). Online and remote learning in higher education institutes: A necessity in light of COVID19 pandemic. Higher Education Studies, 10(3), 16-25. https://doi.org/10.5539/hes.v10n3p16

Almaiah, M. A., Al-Khasawneh, A., \& Althunibat, A. (2020). Exploring the critical challenges and factors influencing the E-learning system usage during COVID-19 pandemic. Education and Information Technologies, 25, 5261-5280. https://doi.org/10.1007/s10639-020-10219-y

Aristovnik, A., Keržič, D., Ravšelj, D., Tomaževič, N., \& Umek, L. (2020). Impacts of the COVID-19 pandemic on life of higher education students: A global perspective. Sustainability, 12(20), 8438. https://doi.org/10.3390/su12208438

Bączek, M., Zagańczyk-Bączek, M., Szpringer, M., Jaroszyński, A., \& Wożakowska-Kapłon, B. (2021). Students' perception of online learning during the COVID-19 pandemic: A survey study of Polish medical students. Medicine, 100(7), e24821. https://doi.org/10.1097/MD.0000000000024821

Beacham, N. A., \& Alty, J. L. (2006). An investigation into the effects that digital media can have on the learning outcomes of individuals who have dyslexia. Computers and Education, 47(1), 74-93. https://doi.org/10.1016/j.compedu.2004.10.006

Beidas, H., Khateb, A., \& Breznitz, Z. (2013). The cognitive profile of adult dyslexics and its relation to their reading abilities. Reading and Writing, 26(9), 1487-1515. https://doi.org/10.1007/ s11145-013-9428-5

Bogdanowicz, M. (2012). Diagnoza dysleksji w wieku dorosłym [Diagnosis of dyslexia in adulthood]. In M. Bogdanowicz (Ed.), Dysleksja w wieku dorostym [Dyslexia in the adulthood] (pp. 99-119). Harmonia Universalis.

Cancer, A., Bonacina, S., Antonietti, A., Salandi, A., Molteni, M., \& Lorusso, M. L. (2020). The effectiveness of interventions for developmental dyslexia: Rhythmic reading training compared with 
hemisphere-specific stimulation and action video games. Frontiers in Psychology, 11, 1158. https:// doi.org/10.3389/fpsyg.2020.01158

Carrillo, C., \& Flores, M. A. (2020). COVID-19 and teacher education: A literature review of online teaching and learning practices. European Journal of Teacher Education, 43(4), 466-487. https:// doi.org/10.1080/02619768.2020.1821184

Carroll, J. M., \& Iles, J. E. (2006). An assessment of anxiety levels in dyslexic students in higher education. British Journal of Educational Psychology, 76, 651-662. https://doi.org/10.1348/000709905X 66233

Cataudella, S., Carta, S., Mascia, M. L., Masala, C., Petretto, D. R., \& Penna, M. P. (2021). Psychological aspects of students with learning disabilities in e-environments: A mini review and future research directions. Frontiers in Psychology, 11, 611818. https://doi.org/10.3389/fpsyg.2020.611818

Chigeza, P., \& Halbert, K. (2014). Navigating e-learning and blended learning for pre-service teachers: Redesigning for engagement, access and efficiency. Australian Journal of Teacher Education, 39(11), 8. https://doi.org/10.14221/ajte.2014v39n11.8

Cicha, K., Rizun, M., Rutecka, P., \& Strzelecki, A. (2021). COVID-19 and higher education: first-year students' expectations toward distance learning. Sustainability, 13(4), 1889. https://doi.org/10.3390/ su13041889

Crawford, J., Butler-Henderson, K., Rudolph, J., Malkawi, B., Glowatz, M., Burton, R., ... \& Lam, S. (2020). COVID-19: 20 countries' higher education intra-period digital pedagogy responses. Journal of Applied Learning and Teaching, 3(1), 1-20. https://doi.org/10.37074/jalt.2020.3.1.7

Daniels, L. M., Goegan, L. D., \& Parker, P. C. (2021). The impact of COVID-19 triggered changes to instruction and assessment on university students' self-reported motivation, engagement and perceptions. Social Psychology of Education, 24, 299-318. https://doi.org/10.1007/s11218-021-09612-3

Debowska, A., Horeczy, B., Boduszek, D., \& Dolinski, D. (2020). A repeated cross-sectional survey assessing university students' stress, depression, anxiety, and suicidality in the early stages of the COVID-19 pandemic in Poland. Psychological Medicine, 1-4. https://doi.org/10.1017/S003329172 $000392 \mathrm{X}$

Demuyakor, J. (2020). Coronavirus (COVID-19) and online learning in higher institutions of education: A survey of the perceptions of Ghanaian international students in China. Online Journal of Communication and Media Technologies, 10(3), e202018. https://doi.org/10.29333/ojcmt/8286

Faul, F., Erdfelder, E., Lang, A.-G., \& Buchner, A. (2007). G*Power 3: A flexible statistical power analysis program for the social, behavioral, and biomedical sciences. Behavior Research Methods, 39, 175-191. https://doi.org/10.3758/BF03193146

Faul, F., Erdfelder, E., Buchner, A., \& Lang, A.-G. (2009). Statistical power analyses using G*Power 3.1: Tests for correlation and regression analyses. Behavior Research Methods, 41, 1149-1160. https:// doi.org/10.3758/BRM.41.4.1149

Fawcett, A. J., \& Nicolson, R. I. (1992). Automatisation deficits in balance for dyslexic children. Perceptual and Motor Skills, 75(2), 507-529. https://doi.org/10.2466/pms.1992.75.2.507

Fawcett, A. J., \& Nicolson, R. I. (2008). Dyslexia and the cerebellum. In G. Reid, A. Fawcett, F. Manis, \& L. Siegel (Eds.), The SAGE handbook of dyslexia. (pp. 11-29). Sage.

Ferrer, E., Shaywitz, B. A., Holahan, J. M., Marchione, K. E., Michaels, R., \& Shaywitz, S. E. (2015). Achievement gap in reading is present as early as first grade and persists through adolescence. The Journal of Pediatrics, 167(5), 1121-1125. https://doi.org/10.1016/j.jpeds.2015.07.045

Forteza-Forteza, D., Rodríguez-Martín, A., Álvarez-Arregui, E., \& Menéndez Álvarez-Hevia, D. (2021). Inclusion, dyslexia, emotional state and learning: Perceptions of Ibero-American children with dyslexia and their parents during the COVID-19 lockdown. Sustainability, 13(5), 2739. https://doi.org/ 10.3390/su13052739

Galuschka, K., Ise, E., Krick, K., \& Schulte-Körne, G. (2014). Effectiveness of treatment approaches for children and adolescents with reading disabilities: A meta-analysis of randomized controlled trials. PLoS ONE, 9(2), e89900. https://doi.org/10.1371/journal.pone.0089900

Galuschka, K., Görgen, R., Kalmar, J., Haberstroh, S., Schmalz, X., \& Schulte-Körne, G. (2020). Effectiveness of spelling interventions for learners with dyslexia: A meta-analysis and systematic review. Educational Psychologist, 55(1), 1-20. https://doi.org/10.1080/00461520.2019.1659794

Gambin, M., Sękowski, M., Woźniak-Prus, M., Wnuk, A., Oleksy, T., Cudo, A., ... \& Maison, D. (2021). Generalized anxiety and depressive symptoms in various age groups during the COVID-19 lockdown in Poland. Specific predictors and differences in symptoms severity. Comprehensive Psychiatry, 105, 152222. https://doi.org/10.1016/j.comppsych.2020.152222 
Hellendoorn, J., \& Ruijssenaars, W. (2000). Personal experiences and adjustment of Dutch adults with dyslexia. Remedial and Special Education, 21(4), 227-239. https://doi.org/10.1177/0741932500 02100405

Hodges, C., Moore, S., Lockee, B., Trust, T., \& Bond, A. (2020). The difference between emergency remote teaching and online learning. Educause Review, 27, 1-12

International Dyslexia Association (2002). Definition of dyslexia. Retrieved from: https://dyslexiaida.org/ definition-of-dyslexia/. Accessed 29 Jan 2021.

Jeffries, S., \& Everatt, J. (2004). Working memory: Its role in dyslexia and other specific learning difficulties. Dyslexia, 10(3), 196-214. https://doi.org/10.1002/dys.278

Kaur, M. (2013). Blended learning-its challenges and future. Procedia - Social and Behavioral Sciences, 93, 612-617. https://doi.org/10.1016/j.sbspro.2013.09.248

Kuhn, H. W. (1955). The Hungarian Method for the assignment problem. Naval Research Logistics Quarterly, 2, 83-97. https://doi.org/10.1002/nav.3800020109

Lamm, O., \& Epstein, R. (1992). Specific reading impairments - are they to be associated with emotional difficulties? Journal of Learning Disabilities, 25(9), 605-615. https://doi.org/10.1177/0022219492 02500910

López-Escribano, C., Suro Sánchez, J., \& Leal Carretero, F. (2018). Prevalence of developmental dyslexia in Spanish University Students. Brain Sciences, 8(5), 82. https://doi.org/10.3390/brainsci80 50082

MacCullagh, L., Bosanquet, A., \& Badcock, N. A. (2017). University students with dyslexia: A qualitative exploratory study of learning practices, challenges and strategies. Dyslexia, 23(1), 3-23. https:// doi.org/10.1002/dys. 1544

Maleńczyk, I., \& Gładysz, B. (2019). Academic E-learning in Poland. Results of a diagnostic survey. International Journal of Research in E-learning, 5, 35-59. https://doi.org/10.31261/IJREL.2019.5. 1.03

Maughan, B., Rutter, M., \& Yule, W. (2020). The Isle of Wight studies: the scope and scale of reading difficulties. Oxford Review of Education, 46(4), 429-438. https://doi.org/10.1080/03054985.2020. 1770064

Menghini, D., Hagberg, G. E., Caltagirone, C., Petrosini, L., \& Vicari, S. (2006). Implicit learning deficits in dyslexic adults: An fMRI study. NeuroImage, 33, 1218-1226. https://doi.org/10.1016/j.neuro image.2006.08.024

Moll, K., Kunze, S., Neuhoff, N., Bruder, J., \& Schulte-Körne, G. (2014). Specific learning disorder: Prevalence and gender differences. PLOS ONE, 9(7), e103537. https://doi.org/10.1371/journal.pone. 0103537

Moojen, S. M. P., Gonçalves, H. A., Bassôa, A., Navas, A. L., de Jou, G., \& Miguel, E. S. (2020). Adults with dyslexia: how can they achieve academic success despite impairments in basic reading and writing abilities? The role of text structure sensitivity as a compensatory skill. Annals of Dyslexia, 70(1), 115-140. https://doi.org/10.1007/s11881-020-00195-w

Moore, J. L., Dickson-Deane, C., \& Galyen, K. (2011). e-Learning, online learning, and distance learning environments: Are they the same? The Internet and Higher Education, 14(2), 129-135. https://doi. org/10.1016/j.iheduc.2010.10.001

Mortimore, T., \& Crozier, W. R. (2006). Dyslexia and difficulties with study skills in higher education. Studies in Higher Education, 31(2), 235-251. https://doi.org/10.1080/03075070600572173

Nelson, J. M., Lindstrom, W., \& Foels, P. A. (2015). Test anxiety among college students with specific reading disability (dyslexia) nonverbal ability and working memory as predictors. Journal of Learning Disabilities, 48(4), 422-432. https://doi.org/10.1177/0022219413507604

Nowakowska, I. (2020). Lonely and thinking about the past: the role of time perspectives, big five traits and perceived social support in loneliness of young adults during COVID-19 social distancing. Current Issues in Personality Psychology, 8(3), 175-184. https://doi.org/10.5114/cipp.2020.97289

Orlov, G., McKee, D., Berry, J., Boyle, A., DiCiccio, T., Ransom, T., ... \& Stoye, J. (2021). Learning during the COVID-19 pandemic: it is not who you teach, but how you teach. Economics Letters, 202, 109812. https://doi.org/10.1016/j.econlet.2021.109812

Pang, L., \& Jen, C. C. (2018). Inclusive dyslexia-friendly collaborative online learning environment: Malaysia case study. Education and Information Technologies, 23(3), 1023-1042. https://doi.org/10. 1007/s10639-017-9652-8

Pape-Neumann, J., van Ermingen-Marbach, M., Grande, M., Willmes, K., \& Heim, S. (2015). The role of phonological awareness in treatments of dyslexic primary school children. ActaNeurobiologiaeExperimentalis, 75, 80-106 
Perelmutter, B., McGregor, K. K., \& Gordon, K. R. (2017). Assistive technology interventions for adolescents and adults with learning disabilities: An evidence-based systematic review and meta-analysis. Computers \& Education, 114, 139-163. https://doi.org/10.1016/j.compedu.2017.06.005

Pham, H. H., \& Ho, T. T. H. (2020). Toward a 'new normal' with e-learning in Vietnamese higher education during the post COVID-19 pandemic. Higher Education Research \& Development, 39(7), 1327-1331. https://doi.org/10.1080/07294360.2020.1823945

Pinkas, J., Jankowski, M., Szumowski, Ł., Lusawa, A., Zgliczyński, W. S., Raciborski, F., ... \& Gujski, M. (2020). Public health interventions to mitigate early spread of SARS-CoV-2 in Poland. Medical Science Monitor: International Medical Journal of Experimental and Clinical Research, 26, e924730-1. https://doi.org/10.12659/MSM.924730.

Pino, M., \& Mortari, L. (2014). The inclusion of students with dyslexia in higher education: A systematic review using narrative synthesis. Dyslexia, 20(4), 346-369. https://doi.org/10.1002/dys. 1484

Pirttimaa, R., Takala, M., \& Ladonlahti, T. (2015). Students in higher education with reading and writing difficulties. Education Inquiry, 6(1), 24277. https://doi.org/10.3402/edui.v6.24277

Półjanowicz, W., Mrugacz, G., Szumiński, M., Latosiewicz, R., Bakunowicz-Łazarczyk, A., Bryl, A., \& Mrugacz, M. (2013). Assessment of the effectiveness of medical education on the Moodle e-learning platform. Studies in Logic, Grammar and Rhetoric, 35(1), 203-214. https://doi.org/10.2478/ slgr-2013-0037

Quick, R. L. (2013). Exploring faculty perceptions toward working with academically vulnerable college students. College Quarterly, 16(4), 3-3

Reid, G. (2016). Dyslexia: A practitioner's handbook. Wiley.

Reis, A., Araújo, S., Morais, I. S., \& Faísca, L. (2020). Reading and reading-related skills in adults with dyslexia from different orthographic systems: a review and meta-analysis. Annals of Dyslexia, 70(3), 339-368. https://doi.org/10.1007/s11881-020-00205-X

Riddick, B., Sterling, C., Farmer, M., \& Morgan, S. (1999). Self-esteem and anxiety in the educational histories of adult dyslexic students. Dyslexia, 5(4), 227-248. https://doi.org/10.1002/(SICI)10990909(199912)5:4\%3c227::AID-DYS146\%3e3.0.CO;2-6

Rogowska, A. M., Kuśnierz, C., \& Bokszczanin, A. (2020). Examining anxiety, life satisfaction, general health, stress and coping styles during COVID-19 pandemic in Polish sample of university students. Psychology Research and Behavior Management, 13, 797-811. https://doi.org/10.2147/PRBM. S266511

Rosak-Szyrocka, J., \& Wojciechowski, P. (2015). E-learning as an effective educational space in Poland: the benefits and disadvantages of studying using Moodle. Journal of Achievements in Materials and Manufacturing Engineering, 73(2), 237-246

Rutter, M., \& Yule, W. (1975). The concept of specific reading retardation. Journal of Child Psychology and Psychiatry, 16(3), 181-197. https://doi.org/10.1111/j.1469-7610.1975.tb01269.x

Serhan, D. (2020). Transitioning from face-to-face to remote learning: Students' attitudes and perceptions of using zoom during COVID-19 pandemic. International Journal of Technology in Education and Science, 4(4), 335-342. https://doi.org/10.46328/ijtes.v4i4.148

Shaywitz, S. E., Fletcher, J. M., Holahan, J. M., Shneider, A. E., Marchione, K. E., Stuebing, K. K., Francis, D. J., Pugh, K. R., \& Shaywitz, B. A. (1999). Persistence of dyslexia: The Connecticut longitudinal study at adolescence. Pediatrics, 104(6), 1351-1359. https://doi.org/10.1542/peds.104.6.1351

Sidor, A., \& Rzymski, P. (2020). Dietary choices and habits during COVID-19 lockdown: Experience from Poland. Nutrients, 12(6), 1657. https://doi.org/10.3390/nu12061657

Smythe, I., \& Everatt, J. (2001). Adult Checklist. Available at: https://cdn.bdadyslexia.org.uk/documents/ Dyslexia/Adult-Checklist-1.pdf?mtime=20190410221643\&focal=none. Retrieved: 26.01.2021.

Snowling, M., Muter, V., \& Carroll, J. (2007). Children at family risk of dyslexia: A follow-up in early adolescence. Journal of Child Psychology and Psychiatry, 48(6), 609-618. https://doi.org/10. 1111/j.1469-7610,2006.01725.x

Snowling, M., Dawes, P., Nash, H., \& Hulme, C. (2012). Validity of a protocol for adult self-report of dyslexia and related difficulties. Dyslexia, 18(1), 1-15. https://doi.org/10.1002/dys.1432

Snowling, M. J., Hulme, C., \& Nation, K. (2020). Defining and understanding dyslexia: past, present and future. Oxford Review of Education, 46(4), 501-513. https://doi.org/10.1080/03054985.2020.17657 56

Stoodley, C. J., \& Stein, J. F. (2013). Cerebellar function in developmental dyslexia. The Cerebellum, 12(2), 267-276. https://doi.org/10.1007/s12311-012-0407-1

Suárez-Coalla, P., \& Cuetos, F. (2015). Reading difficulties in Spanish adults with dyslexia. Annals of Dyslexia, 65(1), 33-51. https://doi.org/10.1007/s11881-015-0101-3 
Suchanska, M., \& Keczkowska, J. (2007). Some aspects of employing the Moodle platform as a tool for enhancing the teaching and learning process. In EUROCON 2007-The International Conference on" Computer as a Tool" (pp. 2465-2467).

Szadziewska, A., \& Kujawski, J. (2017). Advantages and disadvantages of the blended-learning method used in the educational process at the faculty of management at the University of Gdansk, in the opinion of undergraduate students. ICERI Proceedings (pp. 3938-3946). https://doi.org/10.21125/ iceri.2017.1051

Szczepańska, A., \& Pietrzyka, K. (2021). The COVID-19 epidemic in Poland and its influence on the quality of life of university students (young adults) in the context of restricted access to public spaces. Journal of Public Health, 1-11. https://doi.org/10.1007/s10389-020-01456-Z

Talarowska, M., Chodkiewicz, J., Nawrocka, N., Miniszewska, J., \& Biliński, P. (2020). Mental health and the SARS-COV-2 Epidemic - Polish research study. International Journal of Environmental Research and Public Health, 17(19), 7015. https://doi.org/10.3390/ijerph17197015

Tamboer, P., Vorst, H. C. M., \& de Jong, P. F. (2017). Six factors of adult dyslexia assessed by cognitive tests and self-report questions: Very high predictive validity. Research in Developmental Disabilities, 71, 143-168. https://doi.org/10.1016/j.ridd.2017.09.010

Taylor, M., Duffy, S., \& Hughes, G. (2007). The use of animation in higher education teaching to support students with dyslexia. Education + Training, 49(1), 25-35. https://doi.org/10.1108/0040091071 0729857

Teddlie, C., \& Yu, F. (2007). Mixed methods sampling: A typology with examples. Journal of Mixed Methods Research, 1(1), 77-100. https://doi.org/10.1177/1558689806292430

Tops, W., Callens, C., Van Cauwenberghe, E., Adriaens, J., \& Brysbaert, M. (2013). Beyond spelling: the writing skills of students with dyslexia in higher education. Reading and Writing, 26(5), 705-720. https://doi.org/10.1007/s11145-012-9387-2

Vinegrad, M. A. (1994). Revised adult dyslexia checklist. Educare, 48, 21-23

Wieczorek, T., Kołodziejczyk, A., Ciułkowicz, M., Maciaszek, J., Misiak, B., Rymaszewska, J., \& Szcześniak, D. (2021). Class of 2020 in Poland: Students' Mental Health during the COVID-19 Outbreak in an Academic Setting. International Journal of Environmental Research and Public Health, 18(6), 2884. https://doi.org/10.3390/ijerph18062884

Woodfine, B. P., Nunes, M. B., \& Wright, D. J. (2008). Text-based synchronous e-learning and dyslexia: Not necessarily the perfect match! Computers and Education, 50(3), 703-717. https://doi.org/10. 1016/j.compedu.2006.08.010

Woodley, A. (1981). The Open University of the United Kingdom. Implementation of higher education reforms. Institute of Education, European Cultural Foundation.

World Health Organization (2015). International Statistical Classification of Diseases and Related Health Problems 10th Revision (ICD-10). Retrieved from: https://icd.who.int/browse10/2019/en. Accessed 31 Mar 2021.

Zajenkowski, M., Jonason, P. K., Leniarska, M., \& Kozakiewicz, Z. (2020). Who complies with the restrictions to reduce the spread of COVID-19?: Personality and perceptions of the COVID-19 situation. Personality and Individual Differences, 166, 110199. https://doi.org/10.1016/j.paid.2020. 110199

Zhao, L. X., Blankinship, B., Duan, Z., Huang, H., Sun, J., \& Bak, T. H. (2020). Comparing face-to-face and online teaching of written and spoken Chinese to adult learners: An Edinburgh-Sheffield case study. International Journal of Chinese Language Teaching, 1(1), 83-98. https://doi.org/10.46451/ ijclt.2020.06.05

Zhu, M., Bonk, C. J., \& Doo, M. Y. (2020). Self-directed learning in MOOCs: Exploring the relationships among motivation, self-monitoring, and self-management. Educational Technology Research and Development, 68, 2073-2093. https://doi.org/10.1007/s11423-020-09747-8

Publisher's note Springer Nature remains neutral with regard to jurisdictional claims in published maps and institutional affiliations. 


\title{
Authors and Affiliations
}

\section{Joanna Zawadka' ${ }^{1}$. Aneta Miękisz ${ }^{2}(1) \cdot$ Iwona Nowakowska ${ }^{3}$. Joanna Plewko ${ }^{4}$. Magdalena Kochańska ${ }^{5}$ (D) Ewa Haman ${ }^{2}$ (D)}

\author{
Aneta Miękisz \\ amiekisz@psych.uw.edu.pl \\ Iwona Nowakowska \\ insd2@aps.edu.pl \\ Joanna Plewko \\ j.plewko@nencki.edu.pl \\ Magdalena Kochańska \\ m.kochanska@ibe.edu.pl \\ Ewa Haman \\ ewa.haman@psych.uw.edu.pl
}

1 Faculty of Polish Studies, University of Warsaw, Krakowskie Przedmieście 26/28, 00-927 Warsaw, Poland

2 Faculty of Psychology, University of Warsaw, Warsaw, Poland

3 Institute of Psychology, The Maria Grzegorzewska University, Warsaw, Poland

4 Laboratory of Language Neurobiology, Polish Academy of Sciences, Nencki Institute of Experimental Biology, Warsaw, Poland

5 Educational Research Institute, Warsaw, Poland 